\title{
Cholera Outbreak Investigation: An Important Perspective in Epidemiology and Public Health
}

\author{
Sriram Chandramohan \\ Department of Public Health, College of Health Sciences Saudi Electronic University, Abha Branch, Kingdom of Saudi Arabia
}

Email address:

drsrirammd@gmail.com

To cite this article:

Sriram Chandramohan. Cholera Outbreak Investigation: An Important Perspective in Epidemiology and Public Health. Journal of Cancer Treatment and Research. Vol. 5, No. 2, 2017, pp. 24-27. doi: 10.11648/j.jctr.20170502.15

Received: October 30, 2016; Accepted: March 13, 2017; Published: March 22, 2017

\begin{abstract}
Outbreak investigation is very challenging and plays a vital role in public health mainly to prevent the spread of diseases and to reduce the mortality due to particular disease. Outbreak investigation establishes a good platform between the Clinicians and the public health professionals.
\end{abstract}

Keywords: Outbreak Investigation, Cholera, Epidemiology

\section{Introduction}

Acute infectious diseases are quite often investigated and the results of such investigation are published in a journal or as a report but such reports do not contain the actual steps followed by the team to investigate the outbreak. [1], [2] Mostly the Epidemiologist and other public health professionals understand and learn the procedures by having a first-hand experience in the field. Cholera is an acute infectious disease caused by the bacterium Vibro. Cholrea by the contamination of water. In 1849 the British physician named John Snow was the first person to explain the association between cholera and contaminated water in London. Later in 1854 a German bacteriologist called Robert Kotch discovered that Vibro. Cholrea is the responsible microbial agent for cholera. Since 1817 there were already six pandemics of cholera and the cholera has affected mostly the whole part of the world. [3], [4] It is mainly associated with safe drinking water and basic sanitation facilities. [5], [6] The Vibro. Cholrea is a motile gram negative bacterium which has got more than 200 serogroups out of which serogroups $\mathrm{O} 1$ and $\mathrm{O} 139$ the reasons for pandemic in human beings. [7] Researchers found that approximately 1.3 to 4 Million cases of cholera are reported every year and 21,000 to 143,000 people die as a result of cholera across the world. [8] The information regarding the outbreak reaches the public health department by the warning giving by the epidemiological surveillance system and the individuals who are directly or indirectly affected by the outbreak. The main purpose of the epidemiological surveillance system is to collect, analyze and interpret the health related data for planning and evaluation of health programs in the country. The data collected by the surveillance system is sometimes incomplete which cannot be used to plan any kind of intervention and at the same time the information from the individuals also not reliable. [9]

The main objective of this paper is to provide the basic theoretical guidance to the entire health care professional for investigation an outbreak of cholera.

\section{Need for Outbreak Investigation [10]}

The outbreak is investigated based on the following factors

- The observed Number of cases is more than the expected number of cases.

- The scale and severity of the outbreak.

- The potential for spread.

- The political and public relations considerations.

- Availability of resources.

\section{Objectives of Cholera Outbreak Investigation}

- To define the magnitude of the cholera outbreak or involvements in terms of time, place and person.

- To find out particular conditions and factors responsible for occurrence of cholera. 
- To find out the causes, sources of cholera infection, mode of transmission.

- To determine control and preventive measures.

- To make recommendations to prevent future occurrences of cholera.

\section{Person Responsible for Outbreak Investigation}

The local health authorities has been given the responsibility of investigating the outbreak but however the investigation can use further resources in case of higher attach rate or the serious complications.

\section{Components of Outbreak Investigation}

Table 1. Components of Outbreak Investigation.

1. Define the problem

- Diagnose the problem and confirm it by laboratory investigation.

- Confirm whether it is an outbreak by making sure that the observed number of cases is higher than the expected number of cases.

2. Descriptive Epidemiology

- Time: Determine the rate and time of onset.

- Place: use spot maps to locate the cases in various location.

- Person: Calculate the attack rate based on age, gender, race, and ethnicity.

3. Formulate the hypothesis based on the source of infection, route of transmission and possible control measures.

4. Test the Hypothesis by conducting the epidemiological, laboratory and environmental investigation whichever is applicable.

5. Draw conclusion and apply the control and preventive measures.

\section{Steps in Outbreak Investigation}

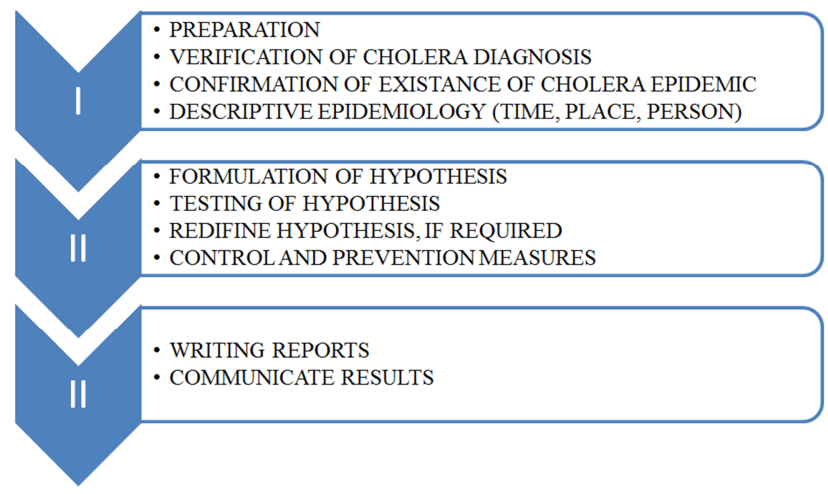

Figure 1. Steps in Outbreak Investigation of Cholera.

\subsection{Preparation [11] [12] [13]}

Collect the pathological and clinical knowledge of cholera. Do the mind mapping about geographical location, climatic conditions, demographic status, socio-economic situation, organization of health services available. Do the Literature review of cholera outbreak in same area or neighboring area and consultation with general physician, pathologist, administrative officer, local politician.

Personnel required: Epidemiologist, Physician, pathologist, Local politician body, Local administration Personnel's. Laptop, mobile, chargers, batteries, mobile satellites.

Other requirements: Oral rehydration solution pouches, I/V fluids (DNS, RL, NS), antibiotics (ciprofloxacin, metronidazole), I/V infusion set, syringes.

\subsection{Verification of Diagnosis [14] [15]}

a) Laboratory investigation: Stool examination, Urine routine, Haemogram and Electrolytes.

b) Environmental investigation: Find out possible sources of infection- water, food, milk etc.

c) Modes of infection: Sources of infection-person infected with vibrio cholera.

The Portal of entry is oral and a route of excretion is the faecal matter. Locate the source of infection. Find out the distance between ware distribution system and sewage disposal system and also look for cross connection between water distribution system and sewage disposal system.

\subsection{Epidemiological and Clinical Investigation [16] [17]}

Find out the mode of occurrence of cholera and the population at risk of getting cholera.

Find out when the first case of cholera appeared? Where it appeared? and who are affected?

Find out the specific signs and symptoms. The specific signs and symptoms for cholera are 30-40 times watery loose motion like plain rice water as a result of it dehydration will happen. Wrinkled skin, Sunken eyes, Change sensorium, Fatigue, lassitude, hypotension.

\subsection{Confirmation of Existence of Cholera Epidemic [17]}

Find out whether cholera is epidemic or endemic in that area.

Whether same type of outbreak occurred before or not?

Find out expected number of cases of cholera from previous outbreak.

If observed numbers of cases of cholera exceed the expected number of cases of previous outbreak, then it is confirmed that there is outbreak of cholera in that particular area.

\subsection{Case Definition and Identification [17]}

a) Confirmed cases:

Watery loose motion like plain rice water more than 30-40 per day, Clear signs of dehydration, Electrolyte imbalance $(\mathrm{Na}, \mathrm{k}, \mathrm{Cl}$ decreased) and Stool examination positive for vibrio cholera.

b) Probable cases:

Watery loose motion less than $30-40$ per day, Signs of dehydration, Stool examination negative for vibrio cholera and Electrolytes may be normal.

c) Possible cases:

All cases of diarrhea and Stool examination may be 
negative for vibrio cholera.

\subsection{Descriptive Epidemiology (Time, Place, and Person) [18]}

a) Time:

When the diarrhea started? What is the peak of occurrence of cholera? Minimum and maximum incubation period? How many days it lasted?

We can use the Epidemic curve. It is used to describe the relation-ship between onset of disease and number of days.

b) Place:

Where the cholera occurred? What is the Geographical area and the Climatic conditions?

\section{c) Person:}

How many are affected? Who are affected? Which age group is mostly affected? Which is the population at risk? Which are the probable, confirmed, possible, primary cases?

\subsection{Formulate and Test Hypothesis [19] [20] [21]}

Etiological agent is vibrio cholera and the Source of infection is the leakage of sewage disposal system to drinking water supply at river.

Mode of transmission is Sewage contamination with drinking water.

Incubation period- few hours up to 5 days.

Diagnosis is cholera and Prognosis is good.

Cross check the hypothesis with clinical, laboratory, environmental and epidemiological investigation reports.

Use of case-control study:-

Cases are those who fulfilled the definition of confirmed cases and Control are those who were exposed to drinking water.

\subsection{Redefine Hypothesis [22]}

If there is poor link or no link between sewage contaminated drinking water and cholera outbreak, then carry out all investigate once again and Use different method of analytic study. Finally cross check all investigations and corelate it with reality.

\subsection{Control and Preventive Measures [23] [24]}

Give Oral Rehydration Solution -citrate and bicarbonate and provide IV Fluids and Antibiotics such as Doxycycline, Tetracycline, Trimethoprim and sulfamethaxazol.

Properly treated drinking water containing free residual chlorine, boiling of water before drinking, sanitary latrines and food sanitation will prevent cholera outbreak.

\subsection{Communicate Result}

Communicate the results of your investigation with the higher official and the local health authority. Inform your findings to the local municipal authorities and media. Record your findings and prepare it as a report so that it will be used for future reference.
Table 2. Reporting and disseminating the Outbreak Investigation.

What: Give an oral Briefing about the outbreak.

Why: To disseminate the information and recommendations.

When: When the investigation started and finished and when you identified the source of infection.

How: How the source of infection was identified and what scientific methods were used?

Where: The appropriate venue of the outbreak

Who: The people responsible for implementing the control and preventive measure.

\section{References}

[1] Goodman RA, Buehler JW, Koplan JP. The epidemiologic field investigation: science and judgment in public health practice. Am J Epidemiol 1990; 132: 916.

[2] MacKenzie WR, Goodman RA. The public health response to an outbreak. Current Issues in Public Health 1996; 2: 1-4.

[3] Barua D. Cholera. Proc R Soc Med 1972; 65: 11-16

[4] Tavana M, Fallah Z, Ataee RA. Is cholera outbreak related to climate factors? Report of seven year study from 21 March 1998-21 March 2004 in Iran. J Med Sci 2006; 6: 480-483. 10.3923/jms.2006.480.483.

[5] WHO fact sheet on cholera. Last up-date November 2008 http://www.who.int/mediacentre/factsheets/fs107/en/.

[6] Cholera outbreak: assessing the outbreak response and improving preparedness. WHO/CDS/CPE/ZFK/2004.4 http://www.who.int/cholera/publications/cholera_outbreak/en/ index.html.

[7] Riedl J, Klose KE: 2002, Vibrio cholerae and cholera: out of the water and into the host. FEMS Microbiol Rev 26: 125139.

[8] WHO fact sheet on cholera. Last up-date October 2016 http:/www.who.int/mediacentre/factsheets/fs107/en/.

[9] Thacker, S. B., \& Berkelman, R. L. (1988). Public health surveillance in the United States. Epidemiologic Reviews, 10, 164-190.

[10] Snow, 1. (1936). Snow on cholera. New York: The Commonwealth Fund. (Originally published as On the mode of communication of cholera in 1855.)

[11] Chesney PJ, Chesney RW, Purdy W, Nelson D, McPherson T, Wand $\mathrm{P}$, et al. Epidemiologic notes and reports: toxic-shock syndrome-United States. MMWR Morb Mortal Wkly Rep 1980; 29: 229-30.

[12] Hertzman PA, Blevins WL, Mayer J, Greenfield B, Ting M, Gleich GJ, et al. Association of eosinophiliamyalgia syndrome with the ingestion of tryptophan. N Engl J Med 1980; 322: 871 .

[13] Steere AC, Malawista SE, Syndman DR, Shope RF, Andman WA, Ross MR, Steele FM. Lyme arthritis: an epidemic of oligoarticular arthritis in children and adults in three Connecticut communities. Arthritis Rheum 1977; 20: 7.

[14] Reingold AL, Kane MA, Murphy BL, Checko P, Francis DP, Maynard JE. Transmission of Hepatitis B by an oral surgeon. J Infect Dis 1982; 145: 262. 7. 
[15] Canter J, Mackey K, Good LS, Roberto RR, Chin J, Bond WW, et al. An outbreak of hepatitis B associated with jet injections in a weight reduction clinic. Arch Intern Med 1990; 150: $1923-7$.

[16] Mahoney FJ, Hoge CW, Farley TA, Barbaree JM, Breiman RF, Benson RF, McFarland LM. Communitywide outbreak of Legionnaires' disease associated with a grocery store mist machine. J Infect Dis 1992; 165: 736.

[17] Koster F, Levy H, Mertz G, Young S, Foucar K, McLaughlin J, et al. Outbreak of acute illness - southwestern United States. MMWR Morb Mortal Wkly Rep 1993; 42: 421-4.

[18] Taylor DN, Wachsmuth IK, Shangkuan Y-H, Schmidt EV, Barrett TJ, Schrader JS, et al. Salmonellosis associated with marijuana: a multistate outbreak traced by plasmid fingerprinting. N Engl J Med 1982; 306: 1249.

[19] Garbe PL, Davis BJ, Weisfeld JS, Markowitz L, Miner P, Garrity F, et al. Nosocomial Legionnaires' disease: epidemiologic demonstration of cooling towers as a source. JAMA 1985; 254: 521.
[20] Tauxe RV, Walters G, Goossen V, VanNoyer R, Vandepitte J, Martin SM, et al. Yersinia enterocolitica infections and pork: the missing link. Lancet 1987; 5: 1129.

[21] Schlech WF, Lavigne PM, Bortolussi RA, Allen AC, Haldane EV, Wort AJ, et al. Epidemic listeriosis: evidence for transmission by food. N Engl J Med 1983; 308: 203.

[22] Fleming DW, Cochi SL, MacDonald KL, Brondum J, Hayes PS, Plikaytis BD, et al. Pasteurized milk as a vehicle of infection in an outbreak of listeriosis. N Engl J Med 1985; 312: 404.

[23] Chambers J, Somerfieldt S, Mackey L, Nichols S, Ball R, Roberts D, et al. Outbreaks of Cyclospora cayetanensis infection-United States, 1996. MMWR Morb Mortal Wkly Rep 1996; 45: 549-51.

[24] Hofman J, Liu Z, Genese C, Wolf G, Manley W, Pilot K, et al. Update: outbreaks of Cyclospora cayetanensis infectionUnited States and Canada, 1996. MMWR Morb Mortal Wkly Rep 1996; 45: 611-2. 